\title{
RADIOGRAPHS IN SHOULDER TRAUMA
}

\author{
J. B. RICHARDSON, A. RAMSAY, J. K. DAVIDSON, I. G. KELLY
}

From the Western Infirmary, Glasgow

\begin{abstract}
It is difficult to establish the diagnosis of an injured shoulder if only one radiographic projection is used. We have compared two lateral projections, the Neer trans-scapular and the apical oblique in 80 patients; the radiographs were presented randomly to 10 casualty officers and nine radiologists. The apical oblique view was found to permit more accurate diagnosis of fractures and of dislocation by both groups.
\end{abstract}

The anatomy of the glenohumeral joint and, in particular, the fact that its plane lies between the sagittal and coronal planes of the body, means that radiographs of this region frequently consist of overlapping images. For this reason it can sometimes be difficult to diagnose bony injury or dislocation at the shoulder. This difficulty is frequently aggravated by the fact that it is the relatively inexperienced casualty officer who is expected to interpret the radiographs.

The Grashey anteroposterior projection displays the glenohumeral joint space without overlap (Ferlic and Clayton 1983), but even with this view posterior dislocation may still go unrecognised (Wolfgang 1982). The need for a second projection, which is routine practice in other areas of the skeleton, has been emphasised by several authors (Bohler 1935; Bernageau and Patte 1979; Sunami et al. 1979; Wallace and Hellier 1983) but enquiries revealed that only two major accident and emergency departments in Scotland routinely used more than one radiographic projection after shoulder injury.

Our own department has used the posterior oblique scapular projection (the "Neer lateral", Neer 1970) as a second projection for many years, but this produces considerable image overlap. Several other "lateral" projections of the glenohumeral joint have been de-

J. B. Richardson, FRCS Ed, Orthopaedic Registrar

A. Ramsay, MB ChB, Radiology Registrar

J. K. Davidson, MD, FRCP Ed, FRCP Glas, FRCR, FRACR (Hon), Consultant Radiologist

I. G. Kelly, MD, FRCS, Senior Lecturer and Honorary Consultant Orthopaedic Surgeon

Western Infirmary, Glasgow G11 6NT, Scotland.

Correspondence should be sent to Mr I. G. Kelly

(C) 1988 British Editorial Society of Bone and Joint Surgery

0301-620X/88/3067 \$2.00

J Bone Joint Surg [Br] 1988;70-B:457-60. scribed and it was the aim of this study to determine which was the most appropriate for routine use in the accident and emergency department. The projections considered were the transthoracic (Vastamaki and Solonen 1980), the axial (Warrick 1965) with its modifications (Rockwood 1984), the apical oblique (Garth, Slappey and Ochs 1984) and the Velpeau (Wallace and Hellier 1983). The transthoracic projection involves image overlap, whilst the axial projection requires some abduction at the shoulder - not always possible after an injury. The apical oblique and Velpeau projections are very similar but the latter requires the patient to be seated.

We required a projection which was easy to perform, involved minimal disturbance of an injured patient, and was readily and easily interpreted by junior medical staff. For these reasons we selected the apical oblique projection to compare with the Neer lateral projection already in use.

\section{PATIENTS AND METHOD}

All patients presenting to the accident and emergency department with acute shoulder problems over a twomonth period were assessed by a casualty officer. If a radiological examination was considered appropriate the radiographer used three projections: an anteroposterior, an apical oblique (Fig. 1) and a Neer lateral (Fig. 2). The preferences of the patient and the radiographer were recorded and the number of repeat radiographs necessary was noted.

The two lateral projections of the 80 consecutive patients included in the study were then reviewed by two radiologists to define the diagnosis in each case (Table I). The films of all the patients with positive radiographic findings, including four copies of the single case of 
posterior dislocation, were combined with four copies of the lateral projections of a normal shoulder, numbered, and randomly presented to 10 casualty officers and nine radiologists. These observers were asked to report on whether they saw a fracture, dislocation or other abnormality or whether they were uncertain as to the diagnosis.

The responses of each group were then analysed to provide an indication of how the radiographic projection influenced the accuracy of diagnosis.

\section{RESULTS}

Table II shows the preferences of the patients and radiographers for the individual projections. The frequency of repeat radiographs was the same for both at $9 \%$ of patients.

The results of the assessments of the radiographs for dislocation and fracture are shown in Table III. The false-negative rate includes those positive radiographs for which an uncertain response was recorded. When an uncertain response was given for a normal radiograph this was added to the false positives. We feel that the radiographs should enable a confident diagnosis of normality as well as abnormality.

The ability of the observers to distinguish between abnormality and normality (i.e. the sensitivity and specificity) of the radiographic projections is shown in Figures 3 and 4 . Sensitivity was calculated as the true positive rate divided by the sum of the true positives and false negatives, and the specificity was calculated by dividing the number of true negatives by the sum of the true negatives and the false positives (Vecchio 1966).

Figure 3 shows that the apical oblique view had a higher sensitivity in the diagnosis of dislocation and the differences between the projections are significant for both the casualty officers $\left(\chi^{2}\right.$ test $\left.p<0.001\right)$ and the radiologists $\left(\chi^{2}\right.$ test $\left.p<0.05\right)$; the latter achieved higher rates with both views.

Figure 4 shows the greater specificity and sensitivity of the apical oblique view in the diagnosis of fractures $\left(\chi^{2}\right.$ test $p<0.01$ ) for both groups of observers.

Other abnormalities, usually calcification, were noted an average of 2.7 times on the apical oblique views and 1.1 times on the Neer lateral projections.

\section{DISCUSSION}

If fractures and dislocations of the shoulder are not to be overlooked two radiographic projections should be used routinely and should provide as much information as possible. They should also be appropriate for use with all patients. Our study is artificial in that it has only assessed the information available from lateral projections without the associated anteroposterior projection and without clinical information. However, only by constructing the

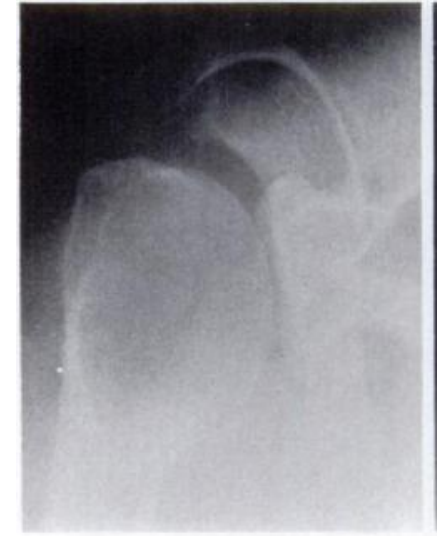

Fig. 1

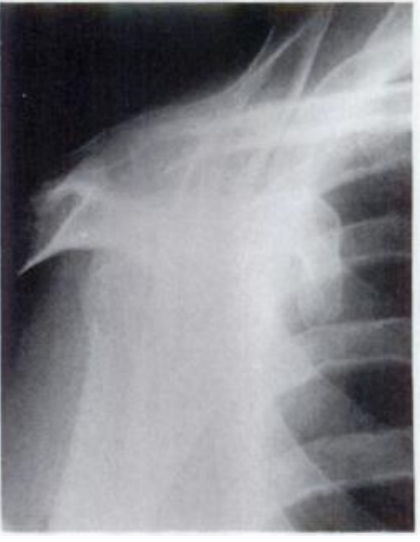

Fig. 2
A pical oblique (Fig. 1) and Neer lateral (Fig. 2) projections of a normal shoulder joint.
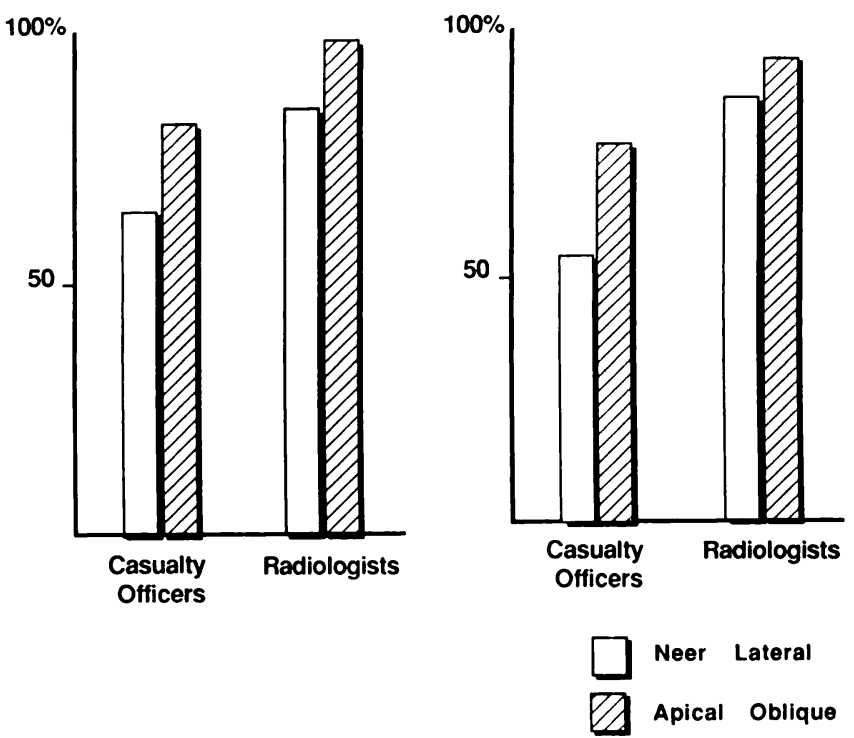

Fig. 3
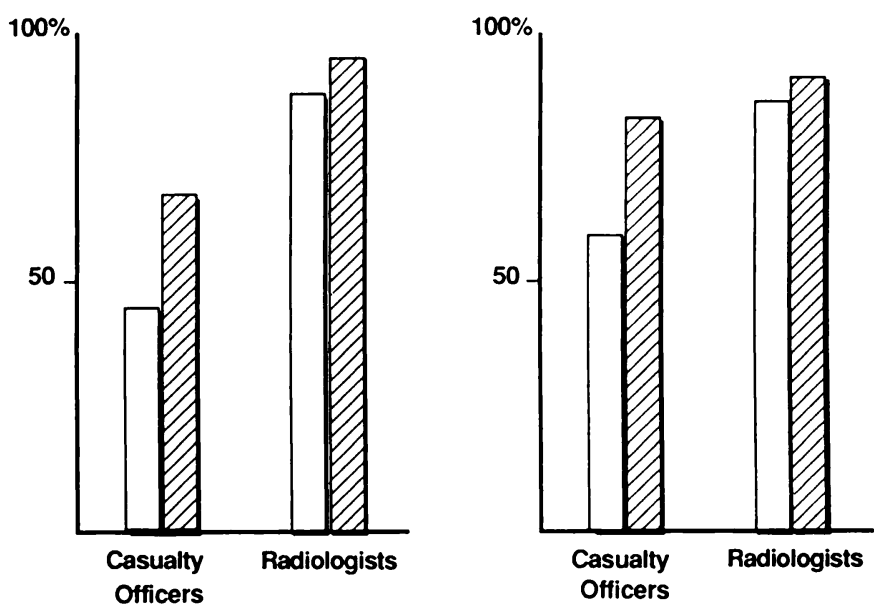

Fig. 4

Sensitivity and specificity of the diagnosis of dislocation (Fig. 3) and fracture (Fig. 4) for casualty officers and radiologists. 
Table I. Initial radiological diagnoses in the study group

\begin{tabular}{lr}
\hline Fracture & 9 \\
Dislocation & \\
$\quad$ anterior & 4 \\
posterior & 1 \\
Soft-tissue calcification & 6 \\
Negative findings & 60 \\
\hline
\end{tabular}

Table II. Percentage acceptability of radiographic views studied

\begin{tabular}{llll}
\hline & Apical & Neer & No preference \\
\hline To patients & 40 & 28 & 32 \\
To radiographers & 39 & 41 & 20 \\
\hline
\end{tabular}

Table III. Combined results of casualty officers and radiologists assessments

\begin{tabular}{lccccc}
\hline & \multicolumn{2}{l}{ True } & & \multicolumn{2}{l}{ False } \\
\cline { 6 - 6 } \cline { 5 - 6 } Diagnosis & Positive & Negative & & Positive & Negative \\
\hline $\begin{array}{l}\text { Dislocation } \\
\text { Apical oblique view }\end{array}$ & 115 & 315 & 67 & 16 \\
Neer view & 96 & 263 & 119 & 35 \\
$\begin{array}{l}\text { Fracture } \\
\text { Apical oblique view }\end{array}$ & 137 & 288 & 54 & 34 \\
Neer view & 110 & 242 & 100 & 61 \\
\hline
\end{tabular}

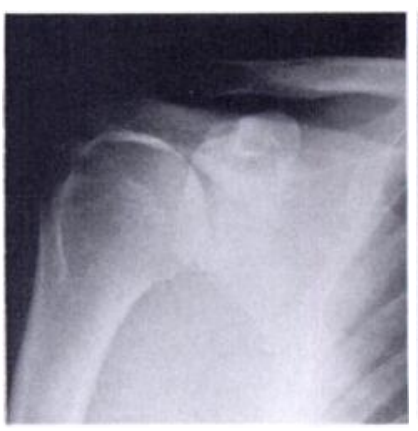

Fig. 5

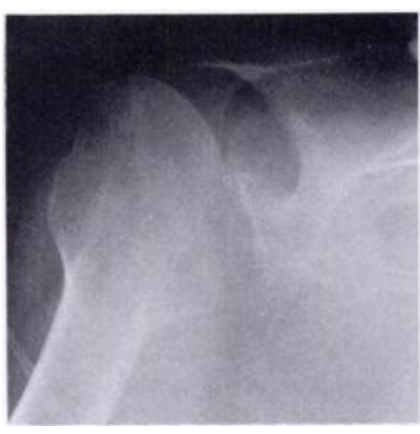

Fig. 6
Posterior dislocation of the shoulder as shown on anteroposterior (Fig. 5) and apical oblique (Fig. 6) projections. study in this way is it possible to obtain an accurate comparison between the two projections chosen.

Both the casualty officers and the radiologists found the apical oblique view to be more specific and more sensitive for the diagnosis of fractures and even more so for dislocations. The number of false positives and uncertain responses with the Neer lateral projection probably reflects its complexity due to image overlap.

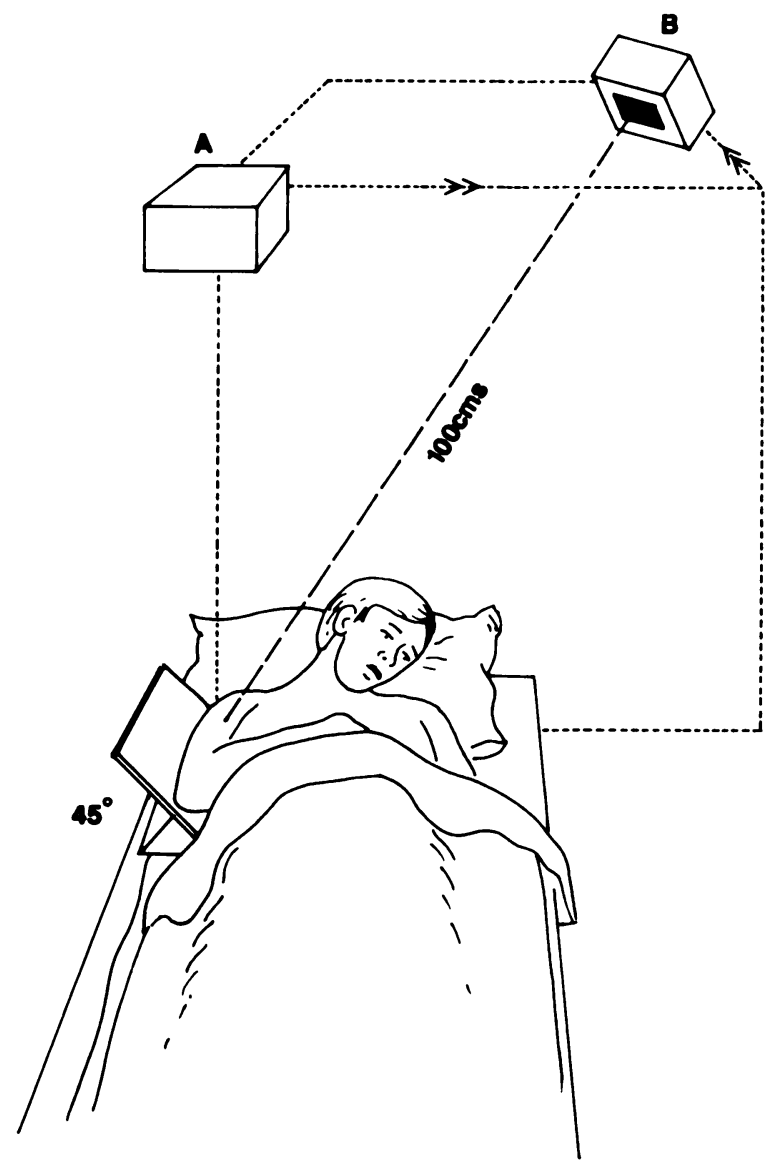

Fig. 7

Method for obtaining an apical oblique projection in a supine patient: (1) take AP as usual from $A$ at $100 \mathrm{~cm}$; (2) imagine a cube of $100 \mathrm{~cm}$ each side and move tube to opposite corner - $B$; (3) centre on glenoid; (4) check anode to film distance is $100 \mathrm{~cm}$.

Casualty officers in particular were more likely to give a false-positive response. The apical oblique view gives a clearer image (Figs 5 and 6) and is associated with a much lower false-positive rate. The distorted appearance of the proximal humerus did not appear to cause undue difficulty. Further, it is possible to carry out the apical oblique projection in the patient with multiple injuries as shown in Figure 7. 
There is, of course, the additional cost of a routine second projection, but this is trivial compared with the cost of compensation for a missed diagnosis, and posterior dislocations are often missed.

Both the Neer lateral and apical oblique projections satisfied our criteria, but the apical oblique permitted more accurate diagnosis in the groups studied. We therefore recommend its use as a routine lateral projection in the assessment of the injured shoulder.

\section{REFERENCES}

Bernageau J, Patte D. Diagnostic radiologique des luxations postérieures de l'épaule. Rer Chir Orthop 1979;65:101-7.

Bloom MH, Obata WG. Diagnosis of posterior dislocation of the shoulder with use of Velpeau axillary and angle-up roentgenographic views. J Bone Joint Surg [Am]1967;49-A :943-9.

Böhler L. Translated by Hey Groves EW. The treatment of fractures. 4th English ed. translated from 4th German ed. Bristol: John Wright \& Sons Ltd. London: Simpkin Marshall Ltd, 1935:23.
Ferlic DC, Clayton ML. Rheumatoid arthritis of the shoulder. In: Evarts CM. Surgery of the musculoskeletal system. New York, etc: Churchill Livingstone, 1983:3.98-108.

Garth WP Jr, Slappey CE, Ochs CW. Roentgenographic demonstration of instability of the shoulder: the apical oblique projection: a technical note. J Bone Joint Surg [Am] $1984 ; 66-A: 1450-3$.

Neer CS II. Displaced proximal humeral fractures. Part I. Classification and evaluation. $J$ Bone Joint Surg [Am] 1970;52-A:1077-89.

Rockwood CA Jr. Subluxations and dislocations about the shoulder. In:Rockwood CA Jr, Green DP, eds. Fractures in adults Vol. 1, 2nd ed. Philadelphia: JB Lippincott, 1984: 826.

Sunami Y, Yasuda S, Tsunashima K, Furukawa S. A case of bilateral primary posterior dislocation of the shoulder. J Jpn Orthop Assoc 1979;53:697-704.

Vastamaki M, Solonen KA. Posterior dislocation and fracturedislocation of the shoulder. Acta Orthop Scand 1980;51:479-84.

Vecchio TJ. Predictive value of a single diagnostic test in unselected populations. New Eng J Med 1966;274:1171-3.

Wallace WA, Hellier M. Improving radiographs of the injured shoulder. Radiography 1983;49:229-33.

Warrick CK. Posterior dislocation of the shoulder joint. Br J Radiol 1965;38:758-61.

Wolfgang GL. Roentgenographic recognition of fracture dislocation of shoulder. Orthop Rev 1982;11(9):149-51. 